\title{
Dry Cough: A Major Limitation with Angiotensin Converting Enzyme Inhibitors in Nepalese Population
}

\author{
Bharat Rawat, Harminder Singh Sodhi, Saroj Dhakal, Bishwo Kumar \\ Shrestha, Deepa Shah, Laxman Bhusal.
}

Nervic Intemational Hospital, Kathmandu, Nepal

\section{Background}

With the growing indications, Angiotensin Converting Enzyme Inhibitors (ACE- I) has become one of the most commonly prescribed medications in the clinical cardiology, Dry hacking cough or persistent throat irritation is one of the known side effects, which is possibly more common in the Himalayan kingdom of Nepal.

\section{Method}

Patients attending cardiology outdoor who had been prescribed ACE-I were included, Out of a total of 532 patients included. 344 (66.15\%) had hypertension, $240(46.15 \%)$ had Coronary Artery Disease, 168 (32.30\%) had Left Ventricular Ejection fraction of less than $40 \%$, and $24(4.61 \%)$ had Chronic Obstructive Airway Disease. Enalapril was used in 252 $(48.46 \%)$ patients with mean daily dose of $7.5 \mathrm{mg}$, lisinopril in 172 (33.07\%) patients with mean daily dose of $5 \mathrm{mg}$; ramipril in 100 (19.23\%) patients with a mean daily dose of $5 \mathrm{mg}$, and ramipril in $4(0.76 \%)$ patients with a mean daily dose of $75 \mathrm{mg}$.

\section{Results}

Overall incidence of persistent dry cough that improved on switching over to Losartan was $22.55 \%$, 56 (25.9\%) patients on enalapril, 40 (18.51\%) patients on lisinopril, and $24(11.11 \%)$ patients on ramipril developed cough that improved after switching over to losartan. 


\section{- NEPALESE HEART JOURNAL •}

\section{Conclusions}

Cough induced by ACE-I is an important clinical limitation that has no known remedy and always needs discontinuation of the medication. Also, the receptor antagonist may essentially not share all the advantages of ACE-I, Higher altitude, widespread use of smoking and possibly some genetic factors may be responsible for the higher incidence of cough in Nepalese population. 